\title{
METHODS, MODELS AND TECHNIQUES FOR DECISION MAKING IN PROJECTS WITH SPECIAL EMPHASIS ON THE BANKING SECTOR
}

\section{Daliborka Simonovska}

\section{Oktomvri, Skopje, Republic of Macedonia}

\section{Nevenka Kiteva Rogleva}

Ss Cyril and Methodius University, Faculty of Electrical Engineering and Information Technologies, Skopje, Republic of Macedonia

OMESTE

JEL Category: C5, D7, D81, G24,

\begin{abstract}
The motivation for this paper is presented by the importance which is given to the project management process or the overall management of the projects as a manner of keeping the enterprise on the desired path to success on one hand, and the decision-making related to the development and implementation of projects on the other; and the lack of extensive and rich literature that pays enough attention to these two processes as a unity, which is necessary to perform the job successfully and according to the plans of the organization. The management of projects would not give the desired results if it is not guided by the decision-making process. This paper will cover all methodologies used for decision-making in the process of project management at a major bank in the Republic of Macedonia. The findings on the functioning of this process are obtained through analysis and research work of the department which is responsible for the management and implementation of all projects. The analysis is conducted prior to the commencement and during the project that the project team is working on, that is the migration to the new system R15.
\end{abstract}

Keywords: Management, banking sector, decision-making process

\section{INTRODUCTION}

This paper is based primarily on author's direct participation in the project, as part of the project team, interviews with the top management, the

The address of the corresponding author: Daliborka Simonovska 耘" simonovska.daliborka@gmail.com project manager and team members, as well as through surveys mainly answered by members who have the biggest stake in the decision-making process during the entire project.

Mostly the research and questions are directed at what methods and techniques are used to arrive at a certain decision if there is any information that 
will ease the process, whether they referred back to a similar situation from the past and the like.

As quoted by the practice, all decisions (no matter whether if it is financial, or election of the members of the project team) will be adopted in accordance with certain procedures and laws which are in turn selected and defined by the organization in accordance with its needs and above all its objectives.

The organization itself has adopted its own rules under which prior to the start of a project predetermined procedures are used for determining the needs of the project, the team members, its activities and responsibilities, further dividing the team into smaller teams following areas of action, etc. These policies and procedures are changed depending on the nature of the project.

The selected and presented set of models and techniques are precisely the ones used by the bank exclusively for these types of projects. This does not mean that they could not be used for other projects, however in order to facilitate their work on the different types of projects they have created a different set of techniques which are used, and according to the needs of the project are modified and supplemented.

The choice for this project was reduced to a few models, models and techniques. Some of them are:

- SWOT analysis - through which we perceive the pros and cons of the project, what can be used as an opportunity, what deserves more attention, and towards what should the negative impact be redirected to;

- Charts - normally used to display a comparison which should help to secure the approval for the idea of starting a project. Charts are usually used to show the benefits (financial performance, the increasingdecreasing number of customers, etc.);

- Tree diagrams - this technique belongs to a package of assorted techniques because it allows you to see each component of a problem, every idea and opportunity or the ability to perceive the capabilities of a candidate, his thinking, decisions, etc.; and
- Surveys and interviews with the employees though not typical and essential tool for decision making, it plays a major role in the execution of a project. Usually, this is a method that is used initially before the official launch of the project and at the end to examine how all stakeholders are satisfied with the new system and the new and improved functionalities.

Through these answers and analyses one can come to a crucial moment which also represents the importance of project management first, and then its weakness without the process of making realistic, timely and accurate decisions. How these decisions help transform a problem into a huge opportunity and thus result in amazing profit performance.

Out of this analysis a conclusion can be derived that also represents the result through which it can be seen how the decision - making process changes the direction of a project - from complete uncertainty, insecurity and possible loss to a project that abounds with information and security in the end, as well as achieving satisfactory profit levels.

\section{PROJECTS AND PROJECT MANAGEMENT}

Projects and project management have been thoroughly studied in the scope of organizations in the last few years. To understand these two terms, it is essential to differentiate between project and project management.

Project management is conceptualized as a procedure which applies tools and methods to direct the accomplishment of project goals (Lundin \& Soederholm, 1995) (Munns \& Bjeirmi, 1996). A project is defined as a temporary nature endeavor, which has a particular goal and is realized by utilizing resources in a certain direction (Lundin \& Soederholm, 1995). The relationship between a certain project and the organization that undertakes it is described as a parent-child relationship where the parent organization is a key stakeholder for the project, but not the only strong and key stakeholder. Furthermore, (Mueller \& Turner, 2007) explain another aspect of projects' nature, identifying projects as drivers that provide 
important advantages for the purpose of the change in organizations. Each project is special and unique, although all projects share the same purpose, which is to create value to enable the success and survival of organizations. Projects are among the major means used by organizations to achieve this aim, which will allow organizations to gain competitive advantage.
A)

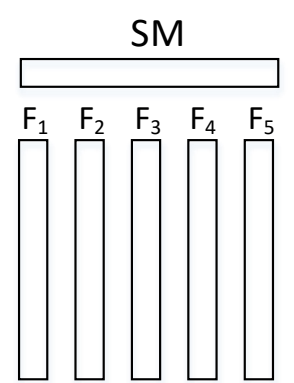

Functional

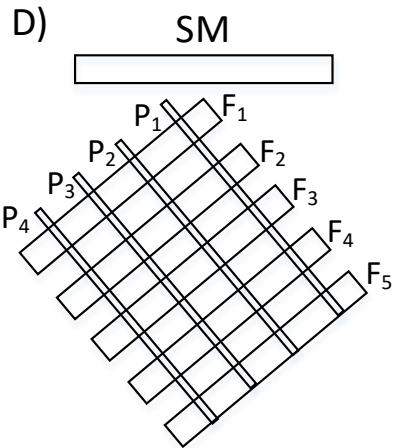

Project Matrix

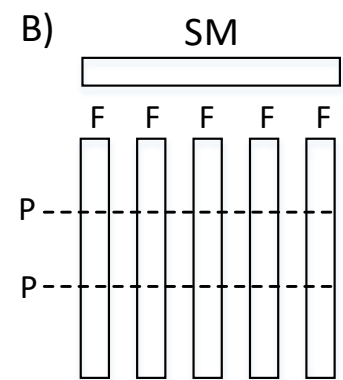

Functional Matrix

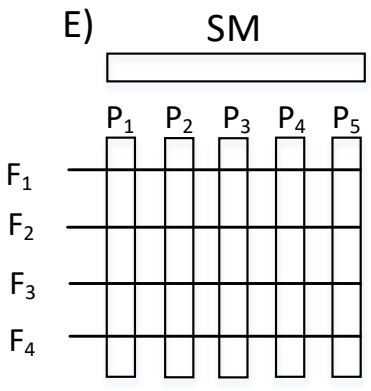

Project-led Organization

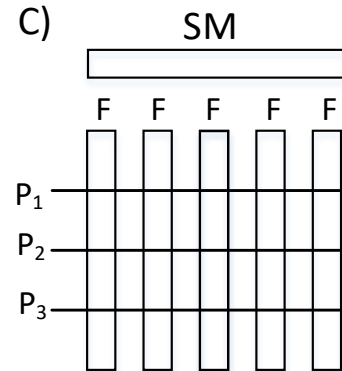

Balanced Matrix

F)

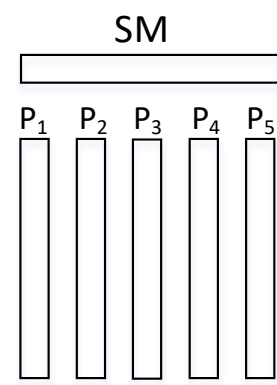

Project-based Organization

Fig. 1 Hobday's six type of organizations

Source: (Hobday, 2000)

Projects can't be claimed successful unless they provide value and satisfy key stakeholders' interests adjusting to the surrounding environment. Moreover, consideration of strategic objectives should be taken into account in understanding the benefits derived from conducting projects. Managing projects should be done in a future perspective and in a way that ensures building a long-term competitive advantage in order to reach a strategic position. Therefore, in order to realize the strategic objectives a holistic view is needed to systematically "align, organize, and execute activities". As a consequence of the increasing importance of projects as means to deliver organizational strategy, many organizations started a process of projectification, developing a project-based structure. To understand the difference between projectized organizations and other forms of organizations, Hobday proposes a framework with the following six types:
From the figure, the F1, F2, F3, F4, and F5 represent the different functions an organization may have (sales, financial,..), while P1, P2, P3, $\mathrm{P} 4$, and P5 represent the projects that that organization may have. As shown in the figure, the types of organizations vary between two extremes: from non-projectized and only functional type $(A)$ to totally projectized type $(F)$. While type $B$ have less project focus and coordination, type $\mathrm{C}$ represents a balance that the organization may have in considering functionality and projects. In type D, the project matrix, projects, and functions have equal importance, thus the project and functional managers have similar power. In type $(E)$, projects have priority and privilege over functions with coordination shown in the links. Finally, type $(F)$ represents the ultimate projectized organization, where projects are the heart of the organization and the business is built around them. 


\section{MAKING EFFECTIVE DECISIONS}

Good decisions lead to great things and a perfect prove of that is Henry Ford's decision to double the wages of his autoworkers, paving the way for the growth of the middle class and changing the U.S. economy for the next century. And on the other hand bad decisions lead to disasters: Kodak's decision not to release the digital camera they invented in 1975, leaving the door open for competitors and leading to the company's bankruptcy. Actions like these force many decision makers to examine the decision-making effectiveness. As J. Davidson Frame points out in his book, Framing Decisions (Frame, 2012) - the attention of the decision maker and the project management team should focus on two things:

- First, it is important to recognize that decision making is a social activity. It is rooted in people and should not be approached as an objective process detached from human factors.

- Second, decision makers must recognize that decisions are the end product of wrestling with constraints: constraints of knowledge, time, resources, skills, political forces, legacy, laws of nature, human laws, ethics, personalities, and more. Effective decision making requires decision makers to surface these constraints and figure out how to craft workable decisions that accommodate them.

Every project starts with a decision. Leaders typically have a bias for action so they like making decisions and often do so with a strong sense of certainty that inspires those around them. Doubt, after all, is neither inspiring nor productive. And yet anyone with any experience knows that decisions are often ill-informed, biased, overoptimistic, and sometimes just plain wrong. The last seven years have revealed massive errors of judgment in strategic thinking, planning, execution, and communication. Poor decisions are made because decision making is difficult and judged by circumstances that keep changing.

Most of the business failures are derivated because the decision makers are ignoring data, people, and details that are available but somehow seemed unimportant at that time are overlooked. Once a decision is made, life isn't static. Change is continuous and new political sensitivities, innovative technologies, and emerging markets change the context in which decisions stand or fall. When a team is in furious execution mode, horizon scanning is impossible, so the decision maker and the team need an early warning system that can alert when the great decision made yesterday is about to become irrelevant today. For the most part, that early warning system is the people.

Every decision is only ever a hypothesis: a belief that an action will have a predicted outcome. But perhaps the toughest part of decision making is remaining open to new information that may reinforce or challenge that prediction. Decision making never really stops. It demands that we continue to share information, review assumptions, and scan for blind spots. For agility, decision making can't be a special event. It has to become a state of mind.

While researching the literature about the connection that exists between the project management and the process of decision making in projects I found out that there is a big gap between them - it exists lots of literature that explain both processes but somehow it is not detailed enough so that it can't be really clear how these two processes work together as a one.

The best way to understand this relationship is a practical example of the decision-making process in a project for functional migration in one of the biggest banking institutions in the country.

The problem is studied through this example (project) because it is the most complex project in which this kind of institutions can get into. Making decisions in this kind of projects is not as easy as "weather to start the project today or tomorrow" but it is more of hard thinking, collaboration, teamwork, researching, and experience. Once the team is ready to begin the "battle" the first decision is:

"What kind of leadership style of decision-making it should be used".

When it comes to this decision the project team (not all of the members but the director and the manager of the department, the advisor for specific questions and the team leaders) gathers together for a meeting in which through active communication and conversation it is decided about the leadership style. This decision represents the base of the whole project as well as the base of the decision-making process. It is an important decision that requires time and 
attention because the future of the project relies on it. This means that it should be chosen the right leadership style who is going to support the project manager and the decision maker - and by doing so it will support and lead the project as well as the decision-making process. Depending on the situation the style can be changed (sometimes it is needed an individual decision and sometimes the best decision is the one chosen by many people).

The basic decision is made with the help of the Vroom-Jago model in which by answering six questions the team comes to the final decision about which leadership style it is going to be used in the project. For every question, all members are supposed to give their explanation why they have chosen the answer and why the chosen answer is better than the other one. Basically, the questions are YES/NO questions but yet can provide such a big value for the bank and for the project. In the picture, you can see how the process was conducted in the bank and how the final YES/NO question leads them to the best leadership style.

According to the given answers, the team has decided that in this case, the best decisionleadership style is the "Collaborative style" in which the team makes almost all of the decisions together as a team, as a unit. After this decision is made then all others are going to be based on the chosen style - meaning that the final decisions will always be a result of the hard work of a few people.

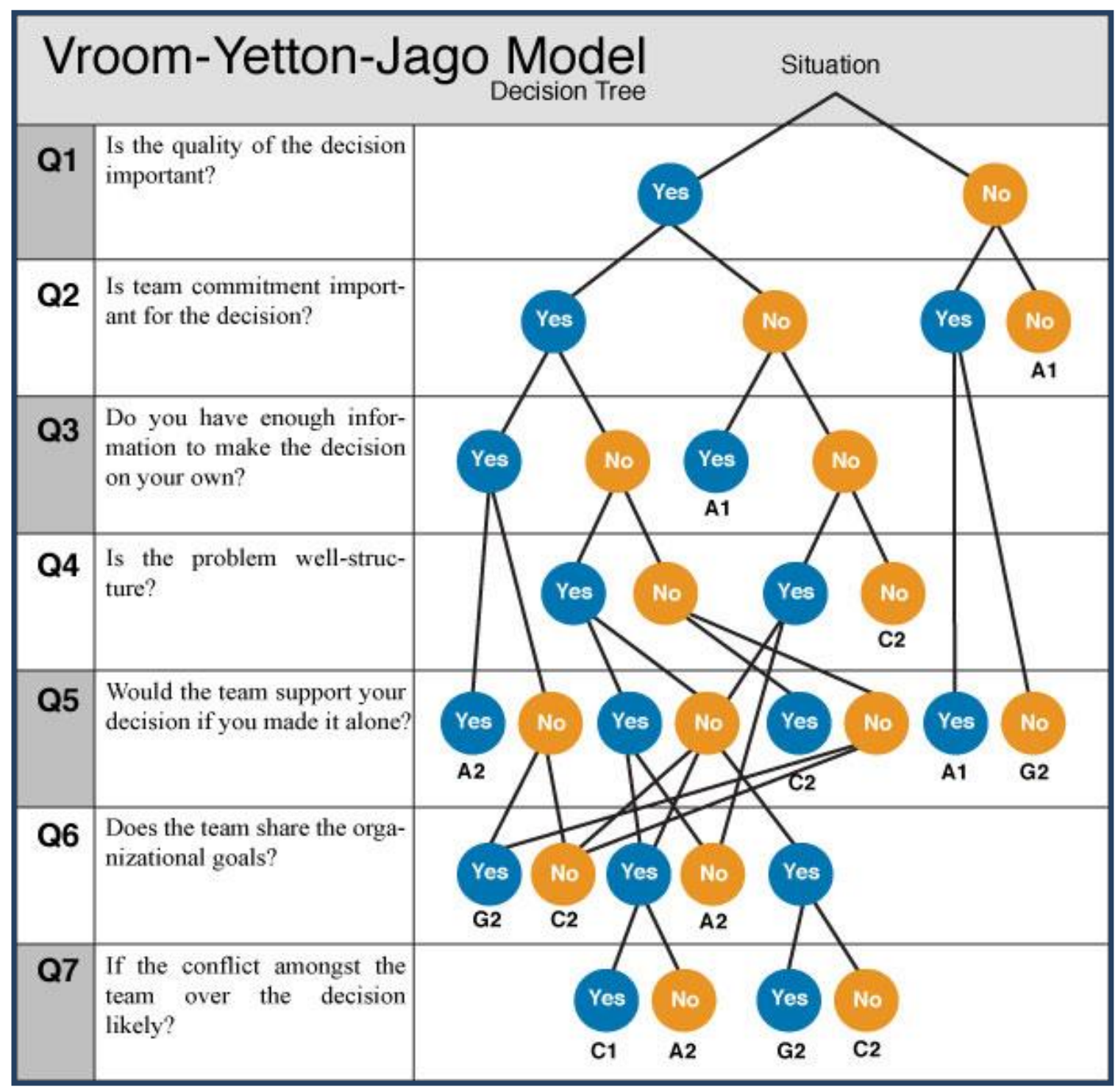

Fig. 2 Vroom-Jago Model (Elmansy, 2015) 
MEST Journal Vol.5 No.1 pp. 105-112

Table 1. Comparison criteria for team members

\begin{tabular}{|l|r|r|r|r|r|r|}
\hline \multirow{2}{*}{ Criteria } & \multicolumn{7}{|l|}{ Person X } & \multicolumn{2}{l|}{ Person Y } \\
\cline { 2 - 7 } & Importance & Points & $\begin{array}{l}\text { Importance } \\
\text { x Points }\end{array}$ & Importance & Points & \multicolumn{2}{l|}{$\begin{array}{l}\text { Importance X } \\
\text { Points }\end{array}$} \\
\hline English language & 50 & 5 & 250 & 50 & 5 & 250 \\
\hline Java & 5 & 0 & 0 & 5 & 5 & 25 \\
\hline C+ & 5 & 0 & 0 & 5 & 5 & 25 \\
\hline $\begin{array}{l}\text { University educated - } \\
\text { ebusiness }\end{array}$ & 40 & 5 & 200 & 40 & 0 & 0 \\
\hline Previous experience & 10 & 5 & 50 & 10 & 3 & 30 \\
\hline $\begin{array}{l}\text { Knowledge about the } \\
\text { bank }\end{array}$ & 20 & 5 & 100 & 20 & 2 & 40 \\
\hline $\begin{array}{l}\text { Knowledge about } \\
\text { their system T24 }\end{array}$ & 30 & 5 & 150 & 30 & 3 & 90 \\
\hline & \multicolumn{2}{|c|}{ Total } & 750 & & Total & 460 \\
\hline
\end{tabular}

The next step in the project is deciding what kind of a people this project needs. Weather successful people with rich experience, college educated people, people who know how to manage risk and uncertainty and so on. This decision is important and the success of the project is closely related to it. Hard working and educated team players are the ones that can make this project moving towards its goals. In the literature making this decision looks very easy but what it comes to the reality seems a little different. According to the team leaders and the HR department of the bank, the best and the most organized method through which it can be compared two or more candidates, their characters and capabilities are the Decision Matrix Analysis. Besides giving the option to compare and evaluate, the method can be used to eliminate the candidates who have shown lower results in the "needed characteristics and capabilities". Basically, the method is based on the following: The director of the sector makes a list of needed characteristic that all candidates must possess and then it evaluates which ones are most important and which are not by giving them the appropriate rank (university educated - 15 points, experience -10 points...).

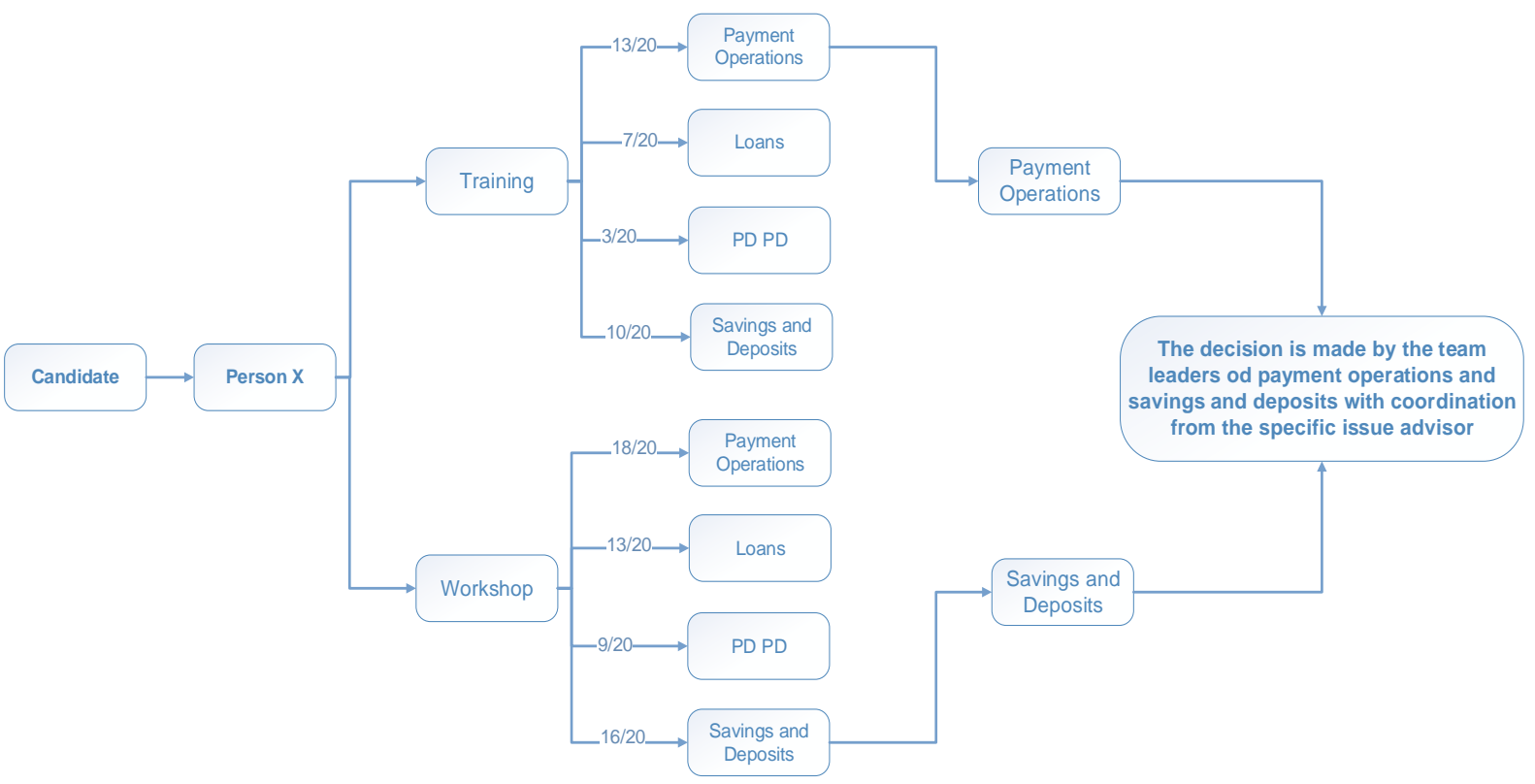

Fig. 3 Decision tree for particular candidate 
After the list is completed all suitable candidates are called in for an interview. On this interview they are asked basic questions about their education, experience, capabilities and so on and every person who is attending the interview is supposed to give grades about everything in the list made by the director. If the education is ranked with 15 points and if the candidate is without university diploma then he would be graded with 1 or 2 then the rank should be multiplied by the given grade. All multiplied numbers should be summed up and the final number shows how suitable every candidate is.

If some of them have the same final number then they are compared and according to the grades in the most wanted characteristics, it is chosen the best one. This process, this decision tool it can be better understand by seeing the table 1 in which there are represented two candidates, the required criteria, its importance for the bank and the points. After the interviews are done it begins the second phase of the process of getting into the final decision - elimination. When compared both candidates it can be seen that the first one person $X$ is the more appropriate than the second one person $Y$. And with that the decision is made - the main project team is formed. Once the selection process is finished, the team leaders are expected to make another final decision which must be made before the official start of the project. The next step is to functionally divide the selected candidates into smaller project teams (according to the different modules in the system of the bank - FT and TELLER transactions, Mortgages, Deposits and so on).

Team leaders have decided that the best way through which they can follow the work of the candidates and then divide them into different functional teams is with the method "Decision Tree". By using this method they have an overview of how the candidates are performing the given tasks, how much time and help they need to do so and how they move forward in order to get to the final step where they would be assigned in particular module.

While performing these tasks from each functional area, team leaders give grades to the candidates and at the end they sum up them and the candidates are assigned in that functional team for which they received the greatest grades. After this decision is made, the decision-making process in the project is not completed. This process is continuous and it happens as many times as required by the project goals and the project success.

The previously mentioned decisions can be grouped as decisions that need to be done before the actual beginning of the project before all the training are begun. Most of the times those decisions are the ones that are considered as routine decisions but this does not mean that they are not complex or that they cannot ruin the success of the project. Choosing the wrong decision leadership style or the wrong people can cause the project manager, the sponsor and all stakeholders a lot of money, time and lost job positions. These three decisions are the basis of the project if chosen right they can guarantee the success of the project, but if chosen the wrong ones they can also guarantee the unsuccessful beginning of such an important project.

In this paper, all other decisions are not mentioned because they depend on the flow of the project. The team may plan them but what will happen is just one big question. So that's why it is very important firstly to create a strong base and then to work on the other decisions. The Strong base means the even stronger end of the project.

\section{CONCLUSIONS}

The methods, models and the techniques used in decision making are a structured approaches which allows to be gained better understanding of the problem or the situation, the changing environment in which the decisions are made, all possible options from which the project manager can choose as well as advice which helps the most productive decision be chosen. On the one hand decision-making process is very complex, but on the other hand, it is a very strong tool through which it can be achieved everything. A careful consideration should be made when: choosing the methods and techniques or whether to base the decision on intuition or on real facts. Every organization should try to always make a decision based on facts but sometimes the situation and the project flow require for an instant decision which probably it is not going to be based on facts but on intuition.

Sometimes the problem is completely new and unknown for the organization and it is much more difficult to find the right solution which will guarantee success. These decisions lead to 
success as well, but the organization needs to pay much more attention and time to control the factors arising from the particular problem.

In the real world, almost all organizations try to use all possibilities in order to create conditions which will revoke big success. This success is not going to be a result only of the properly selected methods, models and techniques but as well as of the capabilities of the project managers to successfully predict if the chosen solutions are appropriate and what kind of success will generate their usage. One important thing to remember is that all decisions can be seen as roadmaps that are paving the way for the project team to the success. Firstly create a strong base and then move towards the obstacles in the project.

\section{WORKS CITED}

Elmansy, R. (2015, Aug 20). Vroom-Yetton-Jago: Deciding How to Decide. Retrieved from Designorate: http://www.designorate.com/vroom-yetton-jagohow-to-decide/

Frame, J. D. (2012). Framing Decisions: Decision-Making that Accounts for Irrationality, People, and Constraints. Jossey-Bass.

Hobday, M. (2000). The project-based organisation: an ideal form for managing complex products and systems? Research Policy, 871-893.

Lundin, R., \& Soederholm, R. (1995). A theory of the temporary organization. Scandinavian Journal of Management, 437-455.

Mueller, R., \& Turner, J. R. (2007). Matching the project manager's leadership style to project type. International Journal of Project Management(25), 21-32.

Munns, A., \& Bjeirmi, B. (1996, Apr). The role of project management in achieving project success. International Journal of Project Management, 14(2), 81-87.

Received for publication:

Revision received:

Accepted for publication:
22.04.2016

31.08 .2016

12.12.2016

\section{How to cite this article?}

Style - APA Sixth Edition:

Simonovska, D., \& Rogleva, N. K. (2017, Jan 15). Methods, models and techniques for decision making in projects with special emphasis on the banking sector. (Z. Cekerevac, Ed.) MEST Journal, 5(1), 105-112. doi:10.12709/mest.05.05.01.13

Style - Chicago Sixteenth Edition:

Simonovska, Daliborka, and Nevenka Kiteva Rogleva. "Methods, models and techniques for decision making in projects with special emphasis on the banking sector." Edited by Zoran Cekerevac. MEST Journal (MESTE) 5, no. 1 (Jan 2017): 105-112. doi:10.12709/mest.05.05.01.13

Style - GOST Name Sort:

Simonovska Daliborka and Rogleva Nevenka Kiteva Methods, models and techniques for decision making in projects with special emphasis on the banking sector [Journal] // MEST Journal/ ed. Cekerevac Zoran. - Belgrade - Toronto : MESTE, Jan 15, 2017. - 1 : Vol. 5. - pp. 105-112.

Style - Harvard Anglia:

Simonovska, D. \& Rogleva, N. K., 2017. Methods, models and techniques for decision making in projects with special emphasis on the banking sector. MEST Journal, 15 Jan, 5(1), pp. 105-112.

Style - ISO 690 Numerical Reference:

Methods, models and techniques for decision making in projects with special emphasis on the banking sector. Simonovska, Daliborka and Rogleva, Nevenka Kiteva. [ed.] Zoran Cekerevac. 1, Belgrade Toronto : MESTE, Jan 15, 2017, MEST Journal, Vol. 5, pp. 105-112. 